\title{
Study of the rain intensity in Athens and Thessaloniki, Greece
}

\author{
C. M. Philandras ${ }^{1}$, P. T. Nastos $^{2}$, A. G. Paliatsos ${ }^{3}$, and C. C. Repapis ${ }^{1}$ \\ ${ }^{1}$ Research Centre for Atmospheric Physics and Climatology, Academy of Athens, Athens, Greece \\ ${ }^{2}$ Laboratory of Climatology and Atmospheric Environment, University of Athens, Athens, Greece \\ ${ }^{3}$ General Department of Mathematics, Technological Education Institute of Piraeus, Piraeus, Greece
}

Received: 28 February 2009 - Revised: 6 February 2010 - Accepted: 16 February 2010 - Published: 10 March 2010

\begin{abstract}
In this study, the mean rain intensity $(\mathrm{mm} / \mathrm{h})$ in Athens and Thessaloniki, Greece, is examined during the period 1930-2007. The daily meteorological data were acquired from the meteorological stations of the National Observatory of Athens (Thissio) and the University Campus of Thessaloniki. These stations have recorded the longest and reliable daily rain time series in Greece.

The trends of the annual and seasonal mean, as well as the maximum rain intensity, are analyzed. On the one hand, all of the time series in Athens present higher figures of mean rain intensity during the period 1990-2007 compared to the period 1930-1990. On the other hand, regarding the time series in Thessaloniki, the mean rain intensity remains in lower level than the respective one in Athens without significant trend at the Confidence Level (CL) 95\%. As far as the annual and seasonal maximum rain intensity is concerned, similar patterns appear. However, the summer maximum rain intensity in Thessaloniki remains at higher levels till 1970's. The atmospheric circulation patterns for the extreme rain intensities show intense negative anomalies centred over Greece and positive anomalies to the north, with centre over Scandinavia.
\end{abstract}

\section{Introduction}

In the recent years, a lot of scientific studies refer to the rain variability and its environmental consequences during the last century (Karl and Knight, 1998; Folland and Karl, 2001; Zhang et al., 2001). Concerning Europe, the trend of the rain totals, appears to be positive in the northern (Forland et al., 1996; Schonwiese and Rapp, 1997) and negative in the southern regions (Schonwiese and Rapp, 1997).

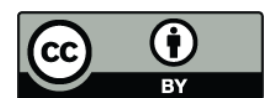

Correspondence to: P. T. Nastos

(nastos@geol.uoa.gr)
Anagnostopoulou et al. (2006), studying the intensity and the number of cyclones for the region of Mediterranean, resulted in a future decrease of the frequency of the severe cyclones $(<1000 \mathrm{hPa})$ at Sea Level Pressure level (SLP), but the future cyclones will be more intense, especially at the $500 \mathrm{hPa}$ level. For the region of Eastern Mediterranean and particularly Greece, studies relative to the trends and the variability of rain time series have been carried out by many researchers (Maheras, 1981; Repapis, 1986; Maheras and Kolyva-Mahera, 1990; Flocas et al., 1990; Amanatidis et al., 1992; Mantis et al., 1994; Metaxas et al., 1999; Brunetti et al., 2001; Nastos et al., 2002; Maheras and Anagnostopoulou, 2003; Paliatsos et al., 2005; Pnevmatikos and Katsoulis, 2006; Feidas et al., 2007; Nastos and Zerefos, 2007, 2008).

The rain variability is described as change in the rain total or change in the frequency of number of rain days or finally, change in the rain intensity. The rain intensity is usually given as the quotient of the monthly rain total by the number of rain days or the rain total within $24 \mathrm{~h}$. However, the rain intensity is of particular importance in every rain event, separately (Dikaiakos and Karapiperis, 1980; Haylock and Nicholls, 2000).

The objective of this work is to analyze the variability and trends of the annual and seasonal mean and maximum rain intensity in Athens, a megacity of approximately 4000000 inhabitants, and in Thessaloniki, the second largest city of Greece with a population of about 1000000 inhabitants at the northern part of Greece.

\section{Data and analysis}

Daily rain totals and their respective duration, regarding all the rain events recorded in the National Observatory of Athens (NOA) for the period 1930-2007 and in the University Campus of Thessaloniki (AUTH) during 1930-2003, are

Published by Copernicus Publications on behalf of the European Geosciences Union. 

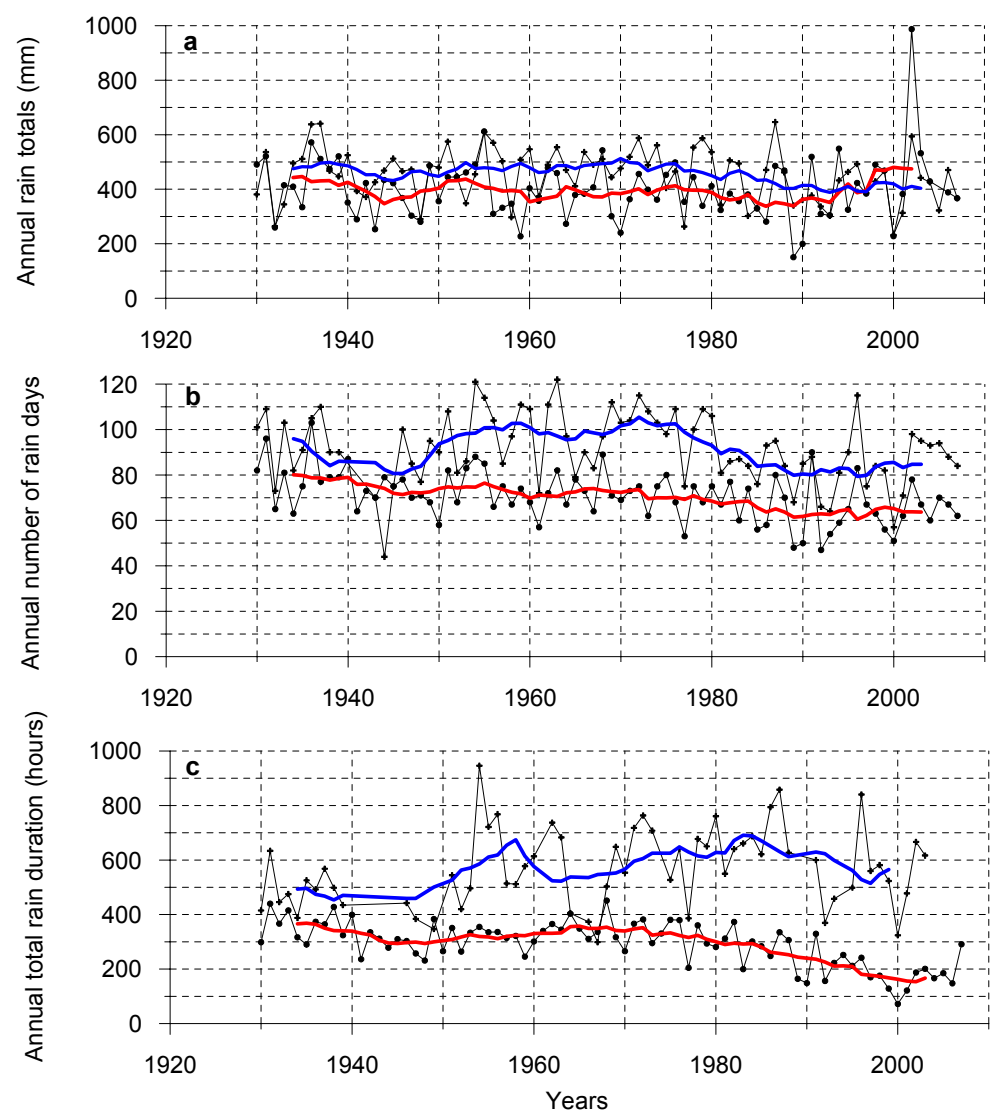

Fig. 1. Time series of annual rain totals (a), annual number of rain days (b) and annual total rain duration for NOA (• circle) and AUTH (+ cross). Red (NOA) and blue (AUTH) curves represent the Gaussian 9 fitting filter.

analyzed. The rainfall intensity time series of Thessaloniki displays missing data during World War II and is also interrupted on 2004. The rain intensity for every rain event is calculated using the formula: $\mathrm{I}_{i}=\mathrm{h}_{i} / \mathrm{d}_{i}$, where $\mathrm{h}_{i}(\mathrm{~mm})$ is the daily rain total and $\mathrm{d}_{i}$ (hours) the duration of the rainfall. In the process, the mean rain intensity $I_{\text {mean }}$ is calculated on annual and seasonal basis, using the formula: $\mathrm{I}_{\text {mean }}=\Sigma \mathrm{I}_{i} / \mathrm{n}$, where $\mathrm{n}$ is the total annual or seasonal number of rain days. Moreover, the maximum rain intensity figures appeared in each year and season were taken into consideration in the performed corresponding time series analysis.

As far as the trends of rain intensity time series are concerned, the Mann-Kendall rank statistic method was applied on the seasonal and annual time series (Mitchell, 1966; Sneyers, 1975; Chu et al., 1994). According to this criterion, every term $x_{i}(i=1, N)$ is compared to all terms following. If $n_{i}$ is the number of terms which exceed the value of $x_{i}$, then the sum (1) is computed and in the process the statistical term $\tau$ (2) is accessed. Then, this statistical term is compared to $(\tau)_{t}(3)$.

$P=\sum_{i=1}^{N-1} n_{\iota}$ $\tau=\frac{4 P}{N(N-1)}-1$

$(\tau)_{t}=0 \pm 1.96 \sqrt{\frac{4 N+10}{9 N(N-1)}}$

where 1.96 is the value for $t$ at the probability point in the Gaussian distribution for $95 \%$ significant level and for the two-tailed test.

\section{Results and discussion}

Figure 1a depicts the time series of the annual rain totals at NOA and AUTH for the period 1930-2007. The annual rain totals at NOA are well correlated with the corresponding values at AUTH; $r=0.40$, statistically significant at the Confidence Level (CL) 95\%. From the beginning of the examined period and until approximately the middle of 1970's both time series present almost parallel course without a clear trend of change, although from year to year high fluctuations appear; the mean annual rainfall reaches approximately the $400 \mathrm{~mm}$ at NOA and $500 \mathrm{~mm}$ at AUTH. Afterwards, the two 
time series present significant decreasing trends (CL 95\%). Concerning NOA, this pattern continues up to 1990 and then an increasing trend is clear with a maximum in 2002; this observed extreme annual rain total $(987.3 \mathrm{~mm})$ is higher than twice as the climatic mean $(402.5 \mathrm{~mm})$ for the entire examined period. On the contrary, concerning AUTH, the decrease is continued up to nowadays and in particular the annual rain total recorded in NOA is higher than the respective one in AUTH within the last decade.

The annual number of rain days in NOA and AUTH presented in Figure 1b, are well correlated $(r=0.60$, statistically significant at $95 \% \mathrm{CL}$ ). A rain day is defined as the day with a $24 \mathrm{~h}$ rain total greater than $0.1 \mathrm{~mm}$. On the one hand, the NOA time series shows a continuous decreasing trend along with some variability up to nowadays. On the other hand, concerning AUTH time series, a significant increasing trend appears from the middle of 1940's until the beginning 1950's, while then the annual rain days remain in high levels until the middle of 1970's and thereafter a significant decreasing trend is obvious until the end of 1980's. Later on, the two examined time series follow parallel courses. The number of rain days are well correlated with the total rain $(r=0.51$ for NOA and $r=0.67$ for AUTH) and with the total rain duration $(r=0.63$ for NOA and $r=0.59$ for AUTH).

Figure 1c demonstrates the time series of the total annual rain duration (hours) in both examined sites (no correlation was found). These time series follow similar patterns to these appearing in Fig. 1b. In this point it is worth mentioning that all time series of the parameters depicted in Fig. 1a-c, during 1970-1990 show decreasing trends, which are likely due to high positive figures of North Atlantic Oscillation observed within this period (Bartzokas et al., 2003).

The annual rain totals at NOA are not correlated with the corresponding values of rain duration moreover, the opposite sign of their trends within the period of the last fifteen years, results in the increase of the mean rain intensity. This is in consequence of the increase of extreme rainfalls as reported also by Nastos and Zerefos (2007). At AUTH the annual rain totals are well correlated with the corresponding duration values $(r=0.42)$.

The annual mean rain intensity ( $\left.\mathrm{I}_{\text {mean }}\right)$ time series at NOA and AUTH are depicted in Fig. 2a. These time series follow almost parallel courses until the late of 1970's with a mean of approximately $1.5 \mathrm{~mm} / \mathrm{h}$. Thereafter, the $\mathrm{I}_{\text {mean }}$ at NOA exhibits a significant increasing trend, reaching a maximum at the beginning of 2000's, which is twice as the preceding mean value. On the contrary the annual $\mathrm{I}_{\text {mean }}$ time series at AUTH does not show any trend of change. During winter and spring (Fig. $2 \mathrm{~b}-\mathrm{c}$ ) the $\mathrm{I}_{\text {mean }}$ time series follow a similar pattern with that of the annual time series, while at NOA during summer and fall (Fig. 2d-e) the increasing significant trend from the middle of 1970's until nowadays (CL 95\%) it is more intense.

The statistical descriptive characteristics of the annual and seasonal $\mathrm{I}_{\text {mean }}$ using Box and Whiskers plots are presented in
Fig. 3, where it is clear that the variability of the rain intensity is higher in summer and fall than in spring and winter, indicative of the relatively higher thunderstorm activity during summer and fall.

Dikaiakos and Karapiperis (1980) studying the rain intensity $(\mathrm{mm} / \mathrm{h})$ at NOA for the period $1930-1977$ found that during the cold period of the year (October-March) the rain intensity varies between 1 and $2 \mathrm{~mm} / \mathrm{h}$, while during the warm period (May-September) between 2 and $3.3 \mathrm{~mm} / \mathrm{h}$. Besides, Tolika et al. (2004) showed that the $24 \mathrm{~h}$ rain totals for the period 1958-2000 show generally negative trends all over Greece, with an exception in the stations of central and southern Greece, especially in summer.

As far as the maximum rain intensity $\left(\mathrm{I}_{\max }\right)$ is concerned, the annual time series (Fig. 4a) mark out extreme intensities, exceeding $20 \mathrm{~mm} / \mathrm{h}$ at NOA, while on the contrary at AUTH, much less cases of extreme figures appear, regarding the same period, 1930-2007. The seasonal $I_{\max }$ time series (Fig. 4b-e) show relative patterns. At this point, it must be signified that, during the recent period (1990-2004) the $I_{\max }$ values exceeding $30 \mathrm{~mm} / \mathrm{h}$ appear only within the dry period of the year.

A physical explanation of the significant increasing trend appearing in the rain intensity time series at NOA is the Urban Heat Island (UHI). The urbanization effect is attributed to the extensive building of Athens around NOA after the Second World War and the rapid increase of the population and the number of vehicles mainly after 1970, resulting mainly to maximum air temperature (an increase $\sim 2{ }^{\circ} \mathrm{C}$ ) and to the warmer seasons of the year (Philandras et al., 1999), with the high amount of suspended particles in the atmosphere of Athens (Kalabokas et al., 2006) probably playing a certain role to the high rain intensity. The mechanical turbulence from increased surface roughness, the addition of sensible heat from the urban warm air and the anthropogenic condensation nuclei floating in the urban air of the developed mega-cities, are the possible main factors, which cause urban induced changes in precipitation (Chandler, 1965). A lot of studies have shown that UHI is associated with convective precipitation in Atlanta (Bornstein and Lin, 2000), in Mexico city (Jauregui and Romales, 1996), in Tel Aviv (Goldreich and Manes, 1979), in Beijing City (Guo et al., 2006), in Tokyo (Yonetani, 1982), in London (Atkinson, 1971), in Ankara (Cicek and Turkoglu, 2005) and in Athens (Nastos and Zerefos, 2007). Moreover, global warming during the recent decades is more likely related to higher water content in the atmosphere (Douville et al., 2002; Trenberth et al., 2003) and this phenomenon results in an increase of the probability of severe convective weather.

During the process, in order to possibly explain the observed dissimilarities of the rain intensity at NOA and AUTH, the patterns of daily composites of the anomalies (mean of the cases minus the total mean of the period 1968-1996) of the sea level pressure (upper panels), geopotential heights at $850 \mathrm{hPa}$ (intermediate panels) and at 

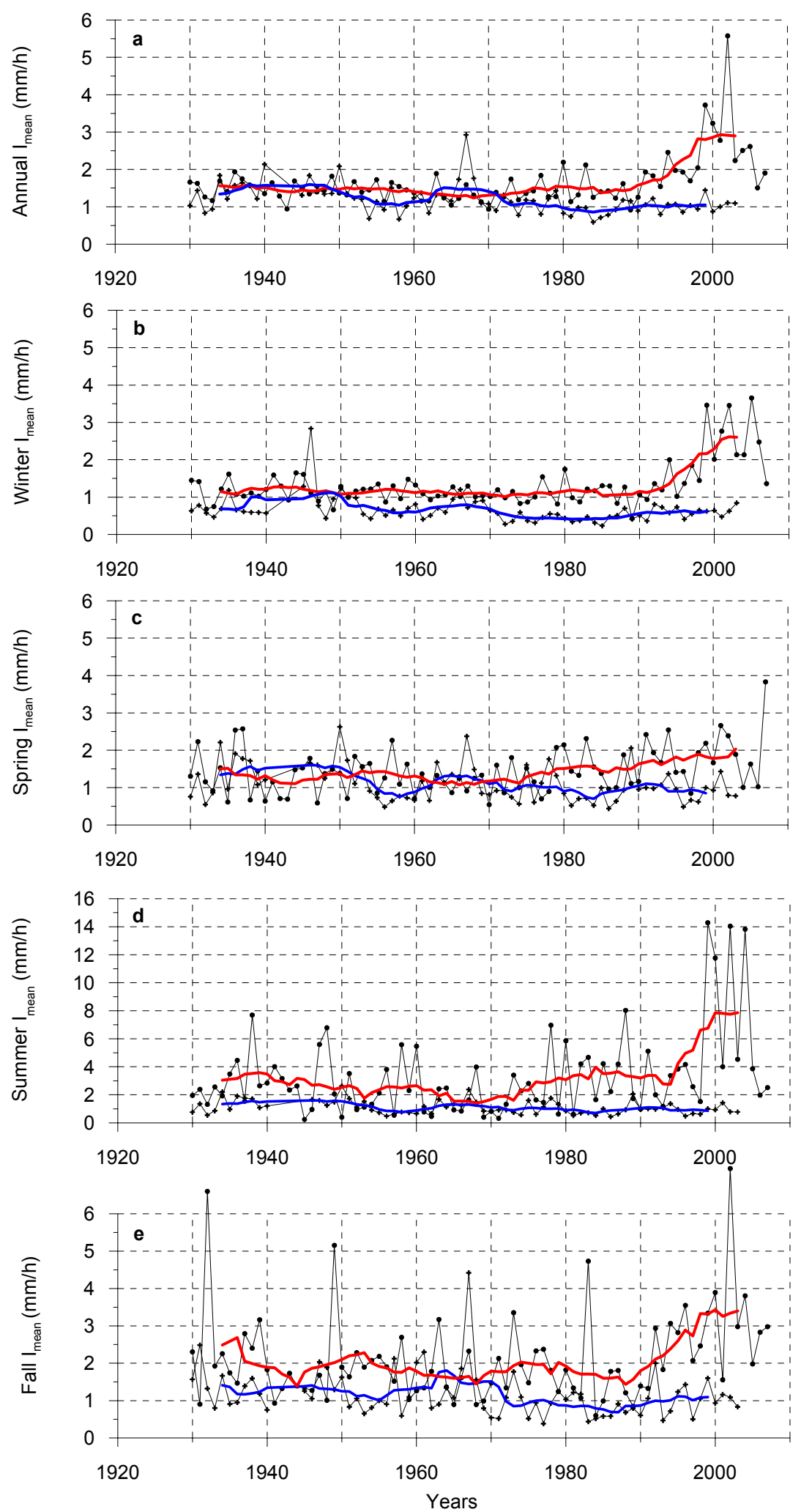

Fig. 2. Time series of annual and seasonal mean rain intensity $\mathrm{I}_{\text {mean }}$ for NOA (• circle) and AUTH (+ cross). Red (NOA) and blue (AUTH) curves represent the Gaussian 9 fitting filter. 

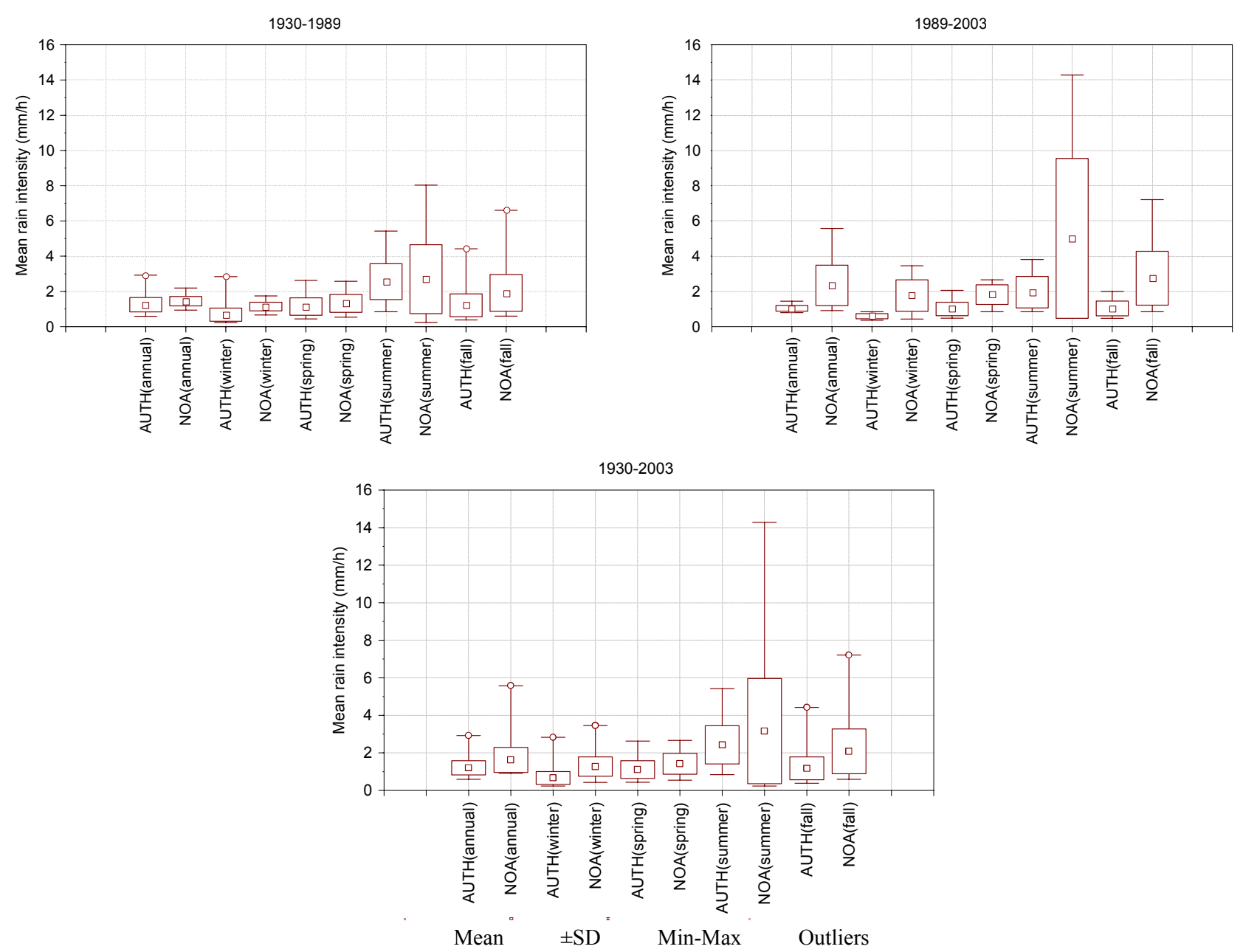

Fig. 3. Box and Whiskers plots for the annual and seasonal mean rain intensity within the sub periods: 1930-1989, 1989-2003 and 19302003 for NOA and AUTH.

$500 \mathrm{hPa}$ (lower panels) from the NCEP/NCAR Reanalysis data (Fig. 5) were examined.

The daily composites concern days with extreme rain intensity greater than the 1 st upper percentile (99\%), which for NOA accounts for $12.8 \mathrm{~mm} / \mathrm{h}$ (42 cases) and for AUTH for $10.1 \mathrm{~mm} / \mathrm{h}$ (48 cases); in this way, the days in which the rain intensity exceeded the aforementioned thresholds were depicted and thereafter the plots of the daily composites of the anomalies were made.

Almost all of the AUTH cases (47 cases) occur during the warm period of the year and for comparison reasons the NOA maps for the warm period cases ( 29 cases) were calculated.

The composite maps show that the extreme rain intensities appear when the pattern of atmospheric circulation is identified by negative anomalies from the surface to the middle troposphere centered above Greece, as it was expected. In the case of AUTH positive anomalies are located further to the north, with center over the Scandinavian countries, extending to the Northeast Atlantic, indicating cold advection towards the Eastern Mediterranean, while the Icelandic low is well deepened. In the case of NOA extreme rain intensities, positive anomalies are also located to the north, with the center over the Scandinavian countries, indicating cold advection towards the Eastern Mediterranean, but the Azores subtropical high is weakened and the Icelandic low is displayed to the northwest. The 500hPa map for the NOA cases showed that positive anomalies are extended towards the Western Mediterranean, while well marked negative ones appear at the Eastern Mediterranean. Similar patterns (not shown) but for the days with extreme rain intensity greater than the 5 th upper percentile $(5.2 \mathrm{~mm} / \mathrm{h}$ for NOA and $4.0 \mathrm{~mm} / \mathrm{h}$ for AUTH) result in the above conclusions for AUTH and NOA. 

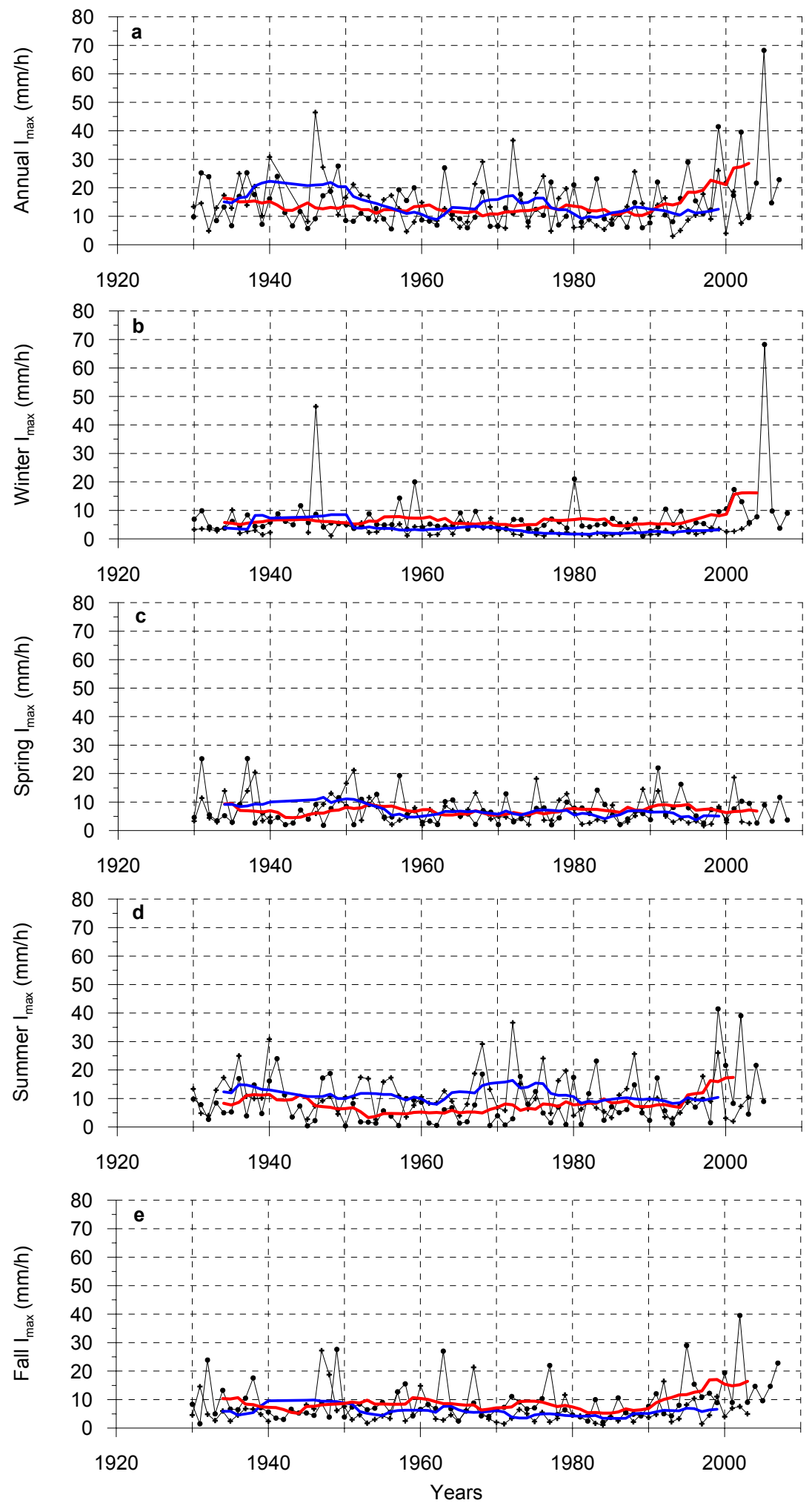

Fig. 4. Time series of annual and seasonal maximum rain intensity $I_{\max }$ for NOA (• circle) and AUTH (+ cross). Red (NOA) and blue (AUTH) curves represent the Gaussian 9 fitting filter. 

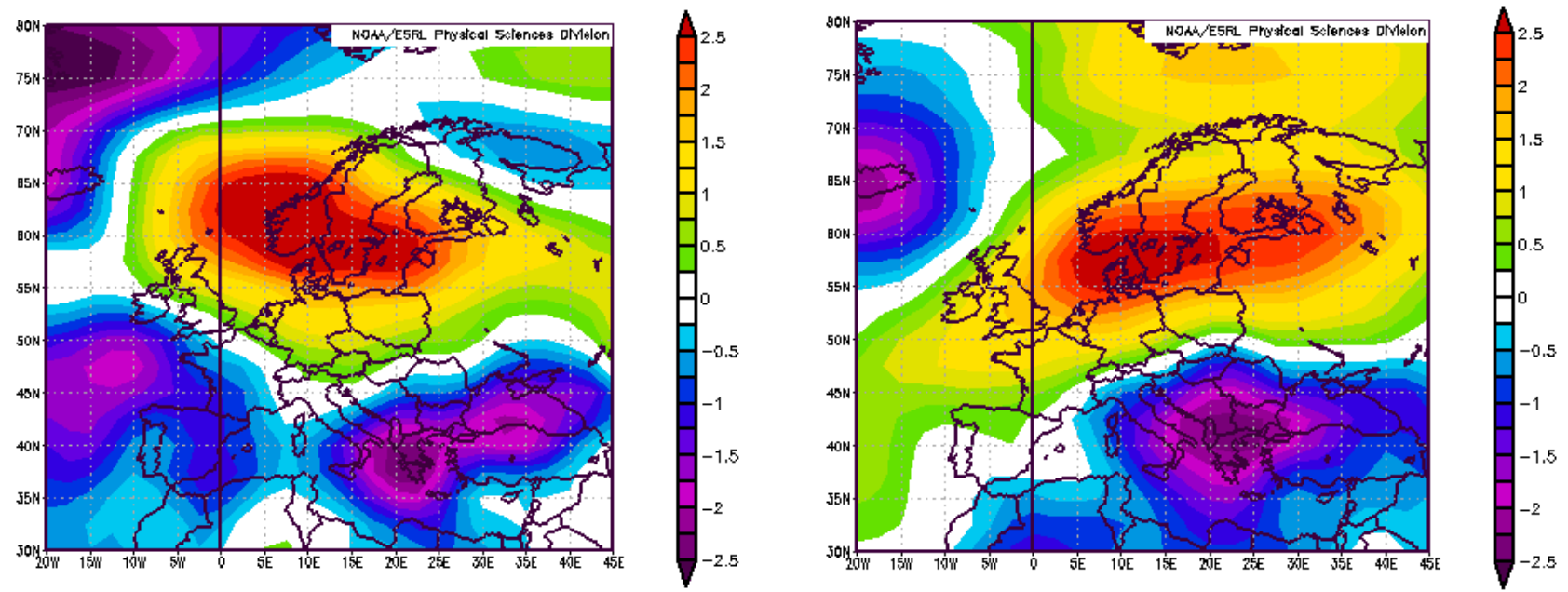

NOA Daily Composites SLP
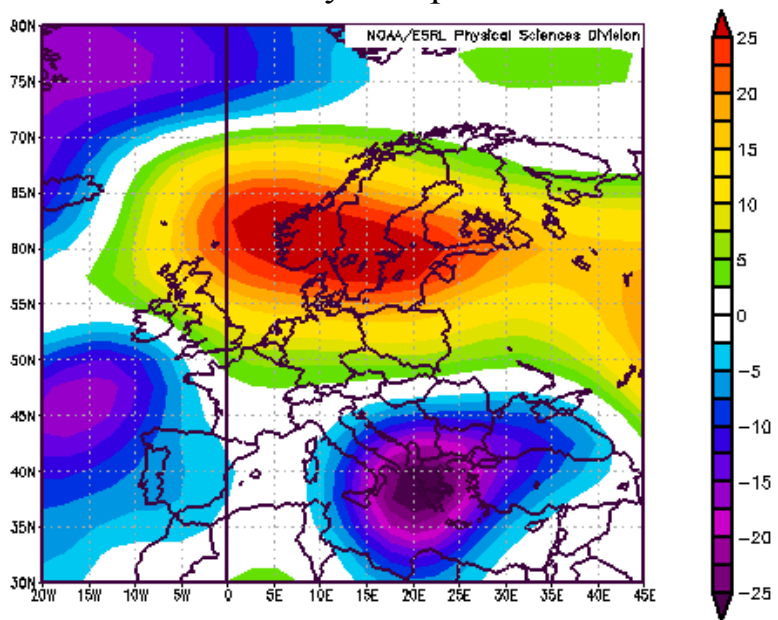

AUTH Daily Composites SLP

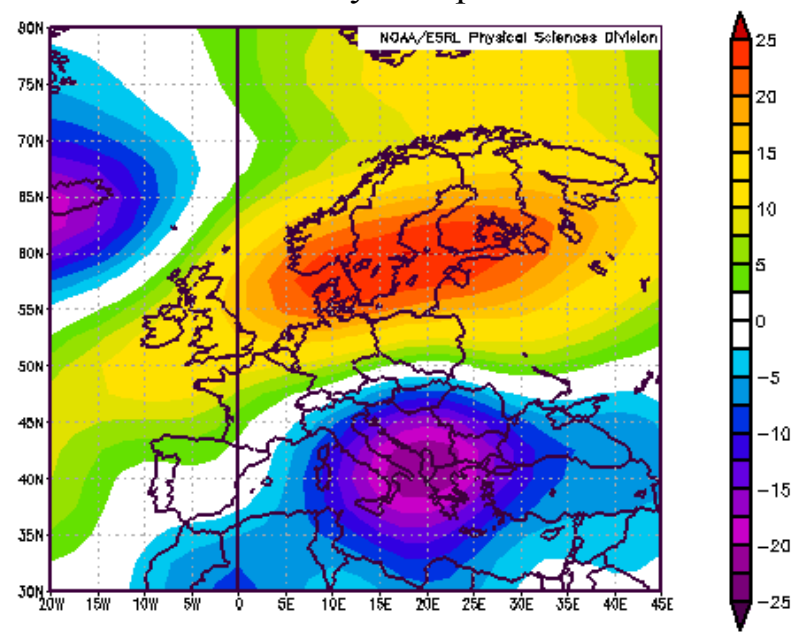

NOA Daily Composites $850 \mathrm{hPa}$

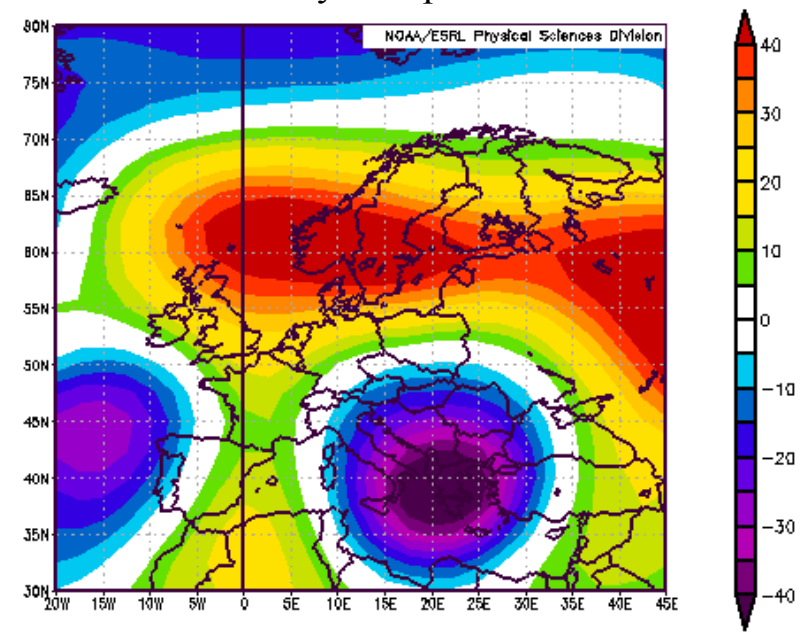

NOA Daily Composites $500 \mathrm{hPa}$

AUTH Daily Composites $850 \mathrm{hPa}$

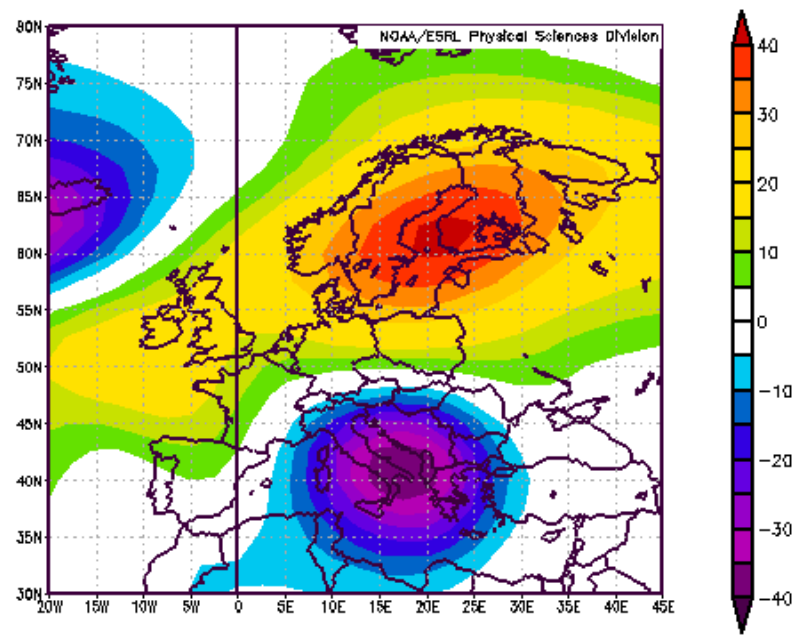

AUTH Daily Composites 500hPa

Fig. 5. Daily composites of the anomalies (mean - total mean of the period 1968-1996) of the sea level pressure (upper panels), geopotential heights at $850 \mathrm{hPa}$ (intermediate panels) and at $500 \mathrm{hPa}$ (lower panels) from the NCEP/NCAR Reanalysis. The daily composites concern days with extreme rain intensity greater than the upper 1st percentile (99\%) during the warm period of the year (29 days for Athens and 47 days for Thessaloniki). 


\section{Conclusions}

The annual and seasonal mean and maximum rain intensity time series at two sites, Athens (NOA) and Thessaloniki (AUTH), for the period 1930-2007, were analyzed. The rain intensity time series at NOA present significant increasing trends, starting in 1990's, during fall and winter and become more intense within the last decade, while the increasing trends begin earlier in 1980's during spring and summer. Regarding the time series at AUTH, they do not present significant trend within the examined period.

The annual total rain duration time series marks out high values during the period 1930-1980 at NOA, while a decreasing trend appears thereafter up today. On the contrary, the respective time series at AUTH present an increasing trend with fluctuations starting at the beginning of 1950's. This study also showed that the variability of the rain intensity is higher in summer and fall than in spring and winter.

The atmospheric circulation patterns for the extreme rain intensities show intense negative anomalies centred over Greece and positive anomalies to the north with centre over Scandinavia. In the case of Thessaloniki, the positive anomalies are extended towards Northeastern Atlantic and the Icelandic Low is well deepened, while in the case of Athens the Azores High is weak.

Acknowledgements. The authors would like to acknowledge the anonymous referees for their constructive and fruitful comments. Edited by: A. Orphanou

Reviewed by: anonymous referees

\section{References}

Amanatidis, G. T., Repapis, C. C., Metaxas, D. A., Paliatsos, A. G., and Bartzis, J. G.: Precipitation decreasing trends in Greece and Cyprus since the middle of our century, in: Global Climate Change Conference, Impacts on Terrestrial Ecosystems, Bad Durkheim, Germany, 1992.

Anagnostopoulou, C., Tolika, K., Flocas, H., and Maheras, P.: Cyclones in the Mediterranean region: Present and future climate scenarios derived from a general circulation model (HadAM3P), Adv. Geosci., 7, 9-14, 2006, http://www.adv-geosci.net/7/9/2006/.

Atkinson, B. W.: Effect of an urban area on the precipitation from a moving thunderstorm, J. Appl. Meteorol., 10(1), 47-55, 1971.

Bartzokas, A., Lolis, C. J., and Metaxas, D. A.: The $850 \mathrm{hPa}$ relative vorticity centers of action for winter precipitation in the Greek area, Int. J. Climatol., 23, 813-828, 2003.

Bornstein, R. and Lin, Q.: Urban heat islands and summertime convective thunderstorms in Atlanta: three cases studies, Atmos. Environ., 34, 507-516, 2000.

Brunetti, M., Maugeri, M., and Nanni, T.: Changes in total precipitation, rainy days and extreme events in northeastern Italy, Int. J. Climatol., 21, 861-871, 2001.

Chu, P. S., Yu, Z. P., and Hastenrath, S.: Detecting climate change concurrent with deforestation in the Amazon basin: Which way has it gone? B. Am. Meteor. Soc., 75, 579-583, 1994.
Cicek, I. and Turkoglu, N.: Urban effects on precipitation in Ankara, Atmosfera, 18(3), 173-187, 2005.

Dikaiakos, J. G. and Karapiperis, L.: The Maxima rain intensities at Athens, Proceedings of the 2nd Hellenic Hydrology Seminar Athens, 239-244, 1980.

Douville, H., Chauvin, F., Planton, S., Royer, J. F., Salas-Melia, D. and Tyteca, S.: Sensitivity of the hydrological cycle to increasing amounts of greenhouse gases and aerosols, Clim. Dynam., 20, 45-68, 2002.

Feidas, H., Noulopoulou, N., Makrogiannis, T., and Bora-Senta, E. Trend analysis of precipitation time series in Greece and their relationship with circulation using surface and satellite data: 19552001, Theor. Appl. Climatol., 87, 155-177, 2007.

Flocas, A. A., Bloutsos, A. A., and Giles, B. D.: Trends and periodicities of rainfall over Greece, in: Climatic Change in the Historical and the Instrumental Periods, edited by: Brazdil, R., 298-305, 1990.

Folland, C. K. and Karl, T. R.: Observed climate variability and change, in: Climate Change 2001: The Scientific Basis, Contribution of Working Group 1 to the Third IPCC Scientific Assessment, edited by: Houghton, J. T., Ding, Y., Griggs, D. J., Noguer, M., van der Linden, P. J., Dai, X., Maskell, K., and Johnson, C. A., Cambridge University Press, Cambridge, UK and New York, NY, USA, 881 pp., 2001.

Forland, E., van Engelen, A., Hanssen-Bauer, I., Heino, R. Ashcroft, J., Dahlström, B., Demarée, G., Frich, P., Jónsson, T., Mietus, M., Müller-Westermeier, G., Pálsdottir, T., Tuomenvirta, H., and Vedin, H.: Changes in "normal" precipitation in the North Atlantic region, Klima Report 7/96, The Norwegian Meteorological Institute, Oslo, 1996.

Goldreich, A. and Manes, Y.: Urban effects of precipitation patterns in the greater Tel-Aviv area, Archiv fur Meteorologie, Geophysik und Bioklimatologie, Serie B, 27(2-3), 213-224, 1979.

Guo, X., Fu, D. and Wang, J.: Mesoscale convective precipitation system modified by urbanization in Beijing City, Atmos. Res., 82, 112-126, 2006.

Haylock, M. and Nicholls, N.: Trends in extreme rainfall indices for an updated high quality data set for Australia, 1910-1998, Int. J. Climatol., 20, 1533-1541, 2000.

Jauregui, E. and Romales, E.: Urban effects on convective precipitation in Mexico City, Atmos. Environ., 30(20), 3383-3389, 1996.

Kalabokas, P. D., Adamopoulos, A. D., Chronopoulos, G., and Viras, L. G.: A study on the characteristic variations of $\mathrm{PM}_{10}$ atmospheric concentrations in Athens, Fresen. Environ. Bull., 15(8b), 846-852, 2006

Karl, T. and Knight, R.: Secular trends of precipitation amount frequency and intensity in the United States, B. Am. Meteor. Soc., 79, 232-241, 1998.

Maheras, P. and Anagnostopoulou, C.: Circulation types and their influence on the international variability and precipitation changes in Greece, in: Mediterranean climate, Variability and trends, edited by: Bolle, H. J., Berlin, Spinger, 215-239, 2003.

Maheras, P. and Kolyva-Mahera, F.: Temporal and Spatial characteristics of annual precipitation over Balkans in the twentieth century, Int. J. Climatol., 10, 495-504, 1990.

Maheras, P.: La variabilite des precipitations dans la mer Egee, Arch. Meteor. Geophy. B, 29, 157-166, 1981. 
Mantis, H. T., Repapis, C. C., Philandras, C. M., Paliatsos, A. G., and Amanatidis, G. T.: The spatial and temporal structure of the precipitation climate the Eastern Mediterranean; Background for a study of Climate Change, in: EUR 17458 - Eastern Europe and Global Change, edited by: Ghazi, A., Mathy, P., and Zerefos, C., Greece, 125-131, 1994.

Metaxas, D. A., Philandras, C. M., Nastos, P. T., and Repapis, C. C.: Variability of Precipitation pattern in Greece during the year, Fresen. Environ. Bull., 8, 1-6, 1999.

Mitchell, J. M., Dzerdzeevskü, B., Flohn, H., Hofmeyr, W. L., Lamb, H. H., Rao, K. N., and Wallén, C. C.: Climatic Change, WMO Technical Note 79, WMO No. 195, TP-100, World Meteorological Organization, Geneva, 79 p., 1966.

Nastos, P. T. and Zerefos, C. S.: On extreme daily precipitation totals at Athens, Greece, Adv. Geosci., 10, 59-66, 2007, http://www.adv-geosci.net/10/59/2007/.

Nastos, P. T. and Zerefos, C. S.: Decadal changes in extreme daily precipitation in Greece, Adv. Geosci., 16, 55-62, 2008, http://www.adv-geosci.net/16/55/2008/.

Nastos, P. T., Philandras, C. M., and Repapis, C. C.: Application of Canonical Analysis to Air Temperature and Precipitation Regimes over Greece, Fresen. Environ. Bull., 11(8), 488-493, 2002.

Paliatsos, A. G., Nastos, P. T., Tzavelas, G., and Panagiotakos, D. B.: Characteristics of precipitation in urban Athens area, from 1891 to 2000, Fresen. Environ. Bull., 14, 422-428, 2005.
Philandras, C. C., Metaxas, D. A., and Nastos, P. T.: Climate Variability and Urbanization in Athens, Theor. Appl. Climatol., 63, 65-72, 1999.

Pnevmatikos, J. D. and Katsoulis, B. D.: The changing rainfall regime in Greece and its impact on climatological means, Meteorol. Appl., 13, 331-345, 2006.

Repapis, C. C.: Temporal fluctuations of precipitation in Greece, Riv. Meteorol. Aeronau., XLVI, 19-25, 1986.

Schonwiese, C. and Rapp, J.: Climate Trend Atlas of Europe based on observations 1891-1990, Kluwer Academic Publishers, Dordrecht, 224 pp., 1997.

Sneyers, R.: Sur l'analyse statistique des series d'observations, Technical Note 143, WMO, Geneva, 1975.

Tolika, K., Anagnostopoulou, C., and Maheras, P.: Trends in Extreme Events acrossCreece in the 2nd half of the 20th Century (Part I-Precipitation), Proceedings of the 7th Panhellenic (International) Conference of Meteorology Climatology and Atmospheric Physics, Nicosia, Cyprus, 484-491, 2004.

Trenberth, K. E., Rasmussen, R. M., and Parsons, D. B.: The changing character of precipitation, B. Am. Meteor. Soc., 84, 12051217, 2003.

Yonetani, T.: Increase in number of days with heavy precipitation in Tokyo urban area, J. Appl. Meteorol., 21(10), 1466-1471, 1982.

Zhang, X., Hogg, W., and Mekis, E.: Spatial and Temporal characteristics of heavy precipitation events in Canada, J. Climate, 14, 1923-1936, 2001. 